\title{
PRÁCTICAS NO LABORALES DE LOS ESTUDIANTES UNIVERSITARIOS Y TITULADOS RECIENTES VERSUS RELACIÓN LABORAL: LA ADECUADA TUTORIZACIÓN COMO FACTOR CLAVE A PROPÓSITO DE LA STSJ DEL PAÍS VASCO DE 14 DE MAYO DE $2019^{1}$
}

\author{
Josep Moreno Gené ${ }^{2}$ \\ Profesor Titular de Derecho del Trabajo y de la SS \\ Universitat de Lleida
}

\begin{abstract}
Siendo el carácter no laboral la característica esencial de estas prácticas no laborales de los estudiantes universitarios y de los titulados recientes, la primera cuestión que se plantea debe ser necesariamente la delimitación entre la prestación de servicios que se desarrolla en el marco de estas prácticas no laborales y la prestación de servicios propia de la relación laboral. A esta ingente tarea de delimitación entre las prácticas no laborales de los estudiantes universitarios y titulados recientes y la relación laboral contribuye de un modo decisivo la STSJ del País Vasco de 14 de mayo de 2019 objeto de este comentario, al conocer de la demanda presentada por la Tesorería General de la Seguridad Social contra una empresa en la que desarrollaban prácticas no laborales diferentes estudiantes universitarios y titulados recientes al amparo del Real Decreto 592/2014 y del Real Decreto 1543/2011.
\end{abstract}

Being the non-work character the essential characteristic of these non-work practices of university students and recent graduates, the first question that arises must necessarily be the demarcation between the provision of services that is carried out within the framework of these non-work practices and the provision of services related to the employment relationship. This enormous task of delimitation between the non-work practices of recent university students and graduates and the employment relationship contributes decisively to the STSJ of the Pais Vasco of May 14, 2019, object of this comment, knowing the demand presented by the General Treasury of the Social Security against a company in which non-work practices were developed by university students and recent graduates under the terms of Royal Decree 592/2014 and Royal Decree $1543 / 2011$.

\footnotetext{
${ }^{1}$ Este trabajo se ha elaborado en el marco del proyecto de investigación RTI2018-097947-B-I00, concedido por el Ministerio de Ciencia, Innovación y Universidades que lleva por título "Nuevas tecnologías, cambios organizativos y trabajo: una visión multidisciplinar".

${ }^{2}$ El autor es miembro del grupo de investigación consolidado reconocido por la Generalitat de Cataluña "Social and Business Research Laboratory" (SBRLab). Ref. 2017 SGR 1572.
} 
Tittle: Internships of graduate students and recent graduates versus labor relationship: the right to tutor as a key factor. Comments on the decision of the Superior Court of Justice the País Vasco, May 14, 2019.

Palabras clave: prácticas no laborales, estudiantes universitarios, titulados recientes, tutorías

Keywords: internship, university students, recent graduates, tutorials

IUSLabor 1/2020, ISSN 1699-2938, p. 111-140

DOI. 10.31009/IUSLabor.2020.101.04

Fecha envío: 13.1.2020 | Fecha aceptación: 25.2.2020

\section{Sumario}

1. A vueltas sobre la naturaleza jurídica de las prácticas no laborales.

2. El alcance de la STSJ del País Vasco de 14 de mayo de 2019.

2.1. El supuesto de hecho y la sentencia de instancia.

2.2. La doctrina contenida en la sentencia del TSJ del País Vasco.

3. El siempre difícil deslinde entre las prácticas no laborales de los estudiantes universitarios y titulados recientes y la relación laboral: la correcta tutorización de las prácticas como factor clave.

4. Referencias bibliográficas. 


\section{A vueltas sobre la naturaleza jurídica de las prácticas no laborales}

Desde hace ya algunas décadas, empresas, administraciones y otras entidades han integrado las estancias prácticas no laborales como parte de su política social y de recursos humanos, lo que ha comportado que en las mismas convivan trabajadores por cuenta ajena con estudiantes universitarios y titulados recientes que realizan sus prácticas formativas recibiendo en ocasiones por las mismas una contraprestación económica en concepto de beca, bolsa, ayuda de estudios, indemnización, estipendio, etcétera ${ }^{3}$.

La realización por parte de los estudiantes universitarios y de los titulados recientes de prácticas no laborales puede suponer un importante valor añadido en su formación, proporcionándoles múltiples y valiosas oportunidades. Así, entre otros efectos beneficiosos, permiten aplicar en el contexto real los conocimientos teóricos y prácticos adquiridos en las aulas; permiten obtener conocimientos relacionados con el ámbito profesional propio de la respectiva titulación; permiten conocer de primera mano los condicionantes con los que se desarrolla el trabajo correspondiente a su titulación en cualquier organización; permiten adaptar sus actitudes y comportamientos al medio profesional, etcétera ${ }^{4}$.

Pero es que además, la realización de estas prácticas académicas externas de los estudiantes universitarios constituye una de las principales pasarelas entre los estudios y el primer empleo, rompiéndose de este modo el círculo vicioso que impide al recién titulado acceder a su primer empleo por carecer de experiencia laboral y al mismo tiempo le impide obtener experiencia porque no puede acceder a su primer empleo ${ }^{5}$. En consecuencia, en no pocas ocasiones, la realización de estas prácticas académicas externas acaba desembocando en la contratación laboral de quienes las realizan ${ }^{6}$, facilitándose de este modo la transición de la educación al trabajo ${ }^{7}$.

\footnotetext{
${ }^{3}$ Sobre este proceso y la tipología de prácticas no laborales vid. MORENO GENÉ, J., "Las estancias prácticas no laborales en el entorno profesional de los jóvenes y su protección social”, en MORENO GENÉ, J. y ROMERo BuRILlo, A.M. (Coords.), Empleo juvenil. Entre el desempleo y la precariedad, Tirant lo Blanch, Valencia, 2016, págs. 237 a 302. Vid. también, Esteve Segarra, A., "Claves para un estatuto de los becarios y la mejora de los períodos de prácticas académicas a partir del análisis de los "stages" franceses", Trabajo y Derecho, núm. 33, 2017, págs. 23 a 38.

${ }^{4} \mathrm{AAVV}$ : El sistema de becas en la primera inserción y su relación con el empleo, Ministerio de Trabajo y Asuntos Sociales, Madrid, 2006, pág. 37, indican que "estas prácticas deben estar pensadas para enriquecer un proceso formativo al añadirle una dimensión práctica aplicada a los saberes aprendidos".

${ }^{5}$ Sobre este círculo vicioso vid. Sempere NaVArro, A.V. (Dir.), Políticas sociolaborales, Tecnos, Madrid, 2005, pág. 226.

${ }^{6}$ En esta misma dirección, FERNÁNDEZ ORRICO, F.J., "La Seguridad Social de quienes participan en programas de formación, y otras tres figuras cercanas", Revista de Información Laboral, núm. 9, 2012,
} 
Como puede observarse, esta vía mediante la que se pretende favorecer la inserción laboral de los jóvenes no consiste en el tradicional fomento de la contratación laboral de los mismos, ya sea mediante la regulación de contratos específicos o mediante el establecimiento de incentivos a su contratación, sino que consiste en la realización de prácticas que no tienen carácter o naturaleza laboral ${ }^{8}$. A tal efecto, se ha indicado que "las prácticas no laborales acaban ganando terreno frente a las contrataciones laborales realizadas bajo la modalidad de contrato en prácticas"9.

El importante incremento del número de estudiantes universitarios y titulados recientes que realizan prácticas no laborales no se ha visto, sin embargo, correspondido por la normativa laboral que apenas ha contemplado esta figura, habiendo sido las diferentes normativas educativas universitarias las encargadas de regular esta materia. A tal efecto, la regulación laboral prácticamente se había limitado a establecer que la participación de los estudiantes y titulados recientes en las prácticas no laborales en ningún caso podía dar lugar al nacimiento de una relación laboral.

indica que "estas prácticas externas constituyen un medio excelente para que los estudiantes puedan obtener su primer empleo, al realizar unas prácticas que permiten a la empresa observar sus habilidades y destrezas que podrían animar a su contratación laboral". También, DE VAL TENA, A.L., "Trabajo en prácticas y prácticas no laborales", Documentación Laboral, núm. 104, 2015, págs. 86 y 87, pone de manifiesto que estas prácticas no laborales pueden ser "una herramienta más al servicio de las políticas activas de empleo".

7 Vid. Todolí Signes, A. "La compleja e insatisfactoria regulación de las prácticas y las becas de trabajo", Trabajo y Derecho, núm. 6, 2015, pág. 62. Vid. también, SÁNCHEZ PÉREZ, J. "Cuatro razones para declarar la inconstitucionalidad e ilegalidad de la regulación reglamentaria de las prácticas no laborales (RD 1543/2011)", Revista General de Derecho y de la Seguridad Social, núm. 38, 2014, pág. 299 y MORENO GENÉ, J. "Las estancias prácticas no laborales en el entorno profesional como mecanismo de transición de los jóvenes de la formación al trabajo", en MORENO GENÉ, J. y FERNÁNDEZ VILLAZÓN, L. (Dirs.) Crisis de empleo, integración y vulnerabilidad social, Thomson Reuters-Aranzadi, Cizur Menor (Navarra), 2017, págs. 245 y ss.

${ }^{8}$ Sobre estas distintas opciones vid. Álvarez Gimeno, R.: "La inserción de los jóvenes profesionales cualificados en el mercado de trabajo", en Estrategia Europea, Estado Autonómico y Política de Empleo. XVIII Congreso Nacional de Derecho del Trabajo y de la Seguridad Social, Ministerio de Trabajo e Inmigración, Madrid, 2008, págs. 755 a 774.

9 SÁNCHeZ PÉREZ, J. "Prácticas no laborales: avances y retrocesos en el derecho del trabajo", en Monereo Pérez, J.L. (Coord.), Retos del Derecho del Trabajo frente al desempleo juvenil, Consejo Andaluz de Relaciones Laborales, Sevilla, 2014. Crítico al respecto se muestra CrUZ VILlalón, J.: "Empleo y crisis económica", en GonZÁlez-Posada Martínez, E. y Molero Marañón, M.L. (Dirs.), Derecho del Trabajo, Constitución y crisis económica. Estudios en homenaje al profesor Fernando Valdés Dal-Ré. Revista Universitaria de Ciencias del Trabajo-Universidad de Valladolid, Valladolid, 2014, pág. 612, que considera que se trata de canales alternativos "que sin ambages cabe calificar de competencia desleal a los contratos formativos que en ese juego de oferta atractiva poco pueden ofrecer por mucho que se altere su vigente régimen legal". 
Esta escasa regulación de las prácticas no laborales de los estudiantes universitarios y de los titulados recientes ha comportado no pocas disfunciones en el desarrollo de esta figura. En primer lugar, ha permitido que se esté produciendo un importante abuso en su utilización por parte de las empresas, que en no pocas ocasiones acuden a estas prácticas para sustituir a trabajadores de la misma con el objetivo de ahorrar costes, no en vano, quienes realizan estas prácticas pueden desarrollar funciones similares a las de un trabajador ordinario sin recibir el correspondiente salario ${ }^{10}$. Ello supone, a su vez, un debilitamiento extremo de la finalidad formativa de estas prácticas no laborales, que queda supeditado a la finalidad productiva de las mismas. En segundo lugar, se produce la circunstancia de que los estudiantes universitarios y titulados recientes van encadenando, una y otra vez, estancias prácticas en el entorno profesional con lo que también queda cuestionada la finalidad de inserción laboral de las mismas o, en otros términos, la consideración como puente entre la formación y el trabajo que se atribuye a estas estancias prácticas ${ }^{11}$.

En este contexto de anomia normativa, en los últimos años se ha procedido a regular con mayor o menor fortuna la figura de las prácticas no laborales de los estudiantes universitarios y de los titulados recientes. A tal efecto, la regulación del primer colectivo se ha llevado a cabo mediante el Real Decreto 592/2014, de 11 de julio, por el que se regulan las prácticas académicas externas de los estudiantes universitarios (en adelante, Real Decreto 592/2014) ${ }^{12}$ y la regulación del segundo colectivo mediante el Real Decreto 1543/2011, de 31 de octubre, por el que se regulan las prácticas no laborales ${ }^{13}$.

Una nota común a esta regulación de las prácticas no laborales de los estudiantes universitarios y titulados recientes es la consideración del carácter no laboral de las mismas. A tal efecto, el artículo 2.3 del Real Decreto 592/2014 establece, en relación con las prácticas académicas externas de los estudiantes universitarios que "dado el carácter formativo de las prácticas académicas externas, de su realización no se derivarán, en ningún caso, obligaciones propias de una relación laboral, ni su contenido

\footnotetext{
${ }^{10}$ De la misma opinión, CRUZ VILLALÓN, J. (2014) "Empleo..." cit., pág. 602, pone de manifiesto que se extienden "usos espurios de las prácticas profesionales como mecanismo de ocultamiento de auténticas actividades productivas, que deberían someterse a una estricta relación contractual laboral retribuida como tal".

${ }^{11}$ Vid. Todolí SigneS, A. “La compleja e insatisfactoria regulación...” cit., pág. 62.

${ }^{12}$ Para un estudio a fondo de esta norma vid. MORENo GENÉ, J. Las prácticas académicas externas de los estudiantes universitarios: aspectos jurídico-laborales y de Seguridad Social, Tirant lo Blanch, Valencia, 2017.

${ }^{13}$ Vid. para un estudio a fondo de esta norma MoRENo GeNÉ, J. "La regulación de las prácticas no laborales en empresa en el Real Decreto 1543/2011: ¿un sucedáneo de contrato en prácticas?", Revista de Trabajo y Seguridad Social. CEF, núm. 347, 2012, págs. 77 a 118.
} 
podrá dar lugar a la sustitución de la prestación laboral propia de puestos de trabajo"; y el artículo 2.2. del Real Decreto 1543/2011 establece que "las prácticas no laborales en las empresas no supondrán, en ningún caso, la existencia de relación laboral entre la empresa y la persona joven".

Siendo el carácter no laboral la característica esencial de estas prácticas no laborales de los estudiantes universitarios y de los titulados recientes, la primera cuestión que se plantea debe ser necesariamente la delimitación entre la prestación de servicios que se desarrolla en el marco de estas prácticas no laborales y la prestación de servicios propia de la relación laboral. A tal efecto, en las diferentes regulaciones de las estancias prácticas en el entorno profesional se echa de menos que, más allá de declarar el carácter no laboral de estas prácticas, se lleve a cabo un deslinde conceptual entre las prácticas que se regulan y la prestación de servicios labora $1^{14}$. En otros términos, las referidas normas se limitan a establecer el carácter no laboral de las prácticas no laborales realizadas por los estudiantes universitarios y los titulados recientes, pero sin definir de forma positiva los rasgos que deben concurrir para que se considere que estas prácticas no constituyen una prestación de servicios laboral ${ }^{15}$. En este punto, como se indicará más adelante, la preponderancia del elemento formativo de las prácticas no laborales se configura como el elemento definidor de las mismas frente al predominio del elemento productivo que caracteriza al contrato de trabajo.

Por lo demás, cabe recordar que tanto el Real Decreto 1543/2011 como el Real Decreto 592/2014 se tratan de normas reglamentarias, de manera que no pueden calificar por sí mismas, porque no tiene rango para ello, la naturaleza jurídica -laboral o extralaboraldel trabajo desarrollado por la persona que realiza las prácticas no laborales, de manera que la actividad de quien las realiza será o no laboral dependiendo de si la misma satisface o no los requisitos de la voluntariedad, ajenidad, dependencia y remuneración exigidos por la legislación laboral y, en particular, por el artículo 1.1 ET. Recuérdese, además, que el artículo 8.1 ET establece una presunción de laboralidad entre "todo el que presta un servicio por cuenta ajena y dentro del ámbito de organización y dirección de otro y el que lo recibe a cambio de una retribución de aquel".

\footnotetext{
${ }^{14}$ Así lo considera CRUZ VILLALÓN, J. “Empleo...” cit., pág. 92, en relación con las prácticas no laborales del Real Decreto 1543/2011.

${ }^{15}$ Molina Hermosilla, O. "Becas de formación convocadas por las universidades: ¿una contribución efectiva a la formación práctica de sus estudiantes? Análisis y propuestas para su adecuada regulación", Revista General de Derecho del Trabajo y de la Seguridad Social, núm. 51, 2018, pág. 59, indica al respecto que "la regulación con que aparecen dotadas estas modalidades formativas en nuestro ordenamiento jurídico no ha contribuido mucho a establecer una clara delimitación entre el recurso legal a las distintas fórmulas de becas y la utilización patológica que se viene haciendo de las mismas".
} 
Pues bien, a esta ingente tarea de delimitación entre las prácticas no laborales de los estudiantes universitarios y titulados recientes y la relación laboral contribuye de un modo decisivo la STSJ del País Vasco de 14 de mayo de 2019 objeto de este comentario $^{16}$, al conocer de la demanda presentada por la Tesorería General de la Seguridad Social contra una empresa en la que desarrollaban prácticas no laborales diferentes estudiantes universitarios y titulados recientes al amparo del Real Decreto 592/2014 y del Real Decreto 1543/2011.

\section{El alcance de la STSJ del País Vasco de 14 de mayo de 2019}

\subsection{El supuesto de hecho y la sentencia de instancia}

En la STSJ del País Vasco de 14 de mayo de 2019 se enjuicia un supuesto en que diferentes estudiantes y titulados recientes realizan prácticas no laborales en una empresa, ya sea, mediante las prácticas académicas externas realizadas en el marco de los estudios de grado, máster y doctorado, previstas en el Real Decreto 592/2014 o las prácticas no laborales contempladas en el Real Decreto 1543/2011, recibiendo como consecuencia de estas prácticas una cantidad económica en concepto de beca.

La empresa en la que se desarrollaban las indicadas prácticas era una empresa tecnológica, que venía desarrollando una aplicación de pago con el terminal telefónico, desarrollando, además del producto, la actividad comercial necesaria para su implantación. Como actividad secundaria se dedicaba a la formación, impartiéndose la misma tanto a nivel interno para los trabajadores como a establecimientos y clientes.

El proceso de captación de los estudiantes y titulados recientes se llevó a cabo enviando una oferta de prácticas a diferentes Universidades -Universidad del País Vasco (en adelante, UPV/EHU) y Universidad de Deusto (en adelante, UD), a la Cámara de Comercio (en adelante CdC) y al Servicio Público de Empleo - LANBIDE. En la citada oferta de prácticas se buscaban candidatos que quisieran desarrollar acciones de marketing online. Asimismo, se solicitaba gente joven con proactividad y con ganas de aprender. Con ello se pretendía, además, crear para el futuro una red fuerte para el negocio.

En el supuesto de los becarios que procedían de la UPV/EHU y de la UD, se formalizaba un convenio entre la empresa y las universidades. En ambos supuestos existía un tutor académico que supervisaba el proceso y recibía la información tanto de alumno como del tutor en la empresa.

16 JUR $2019 \backslash 227150$. 
En el caso de la UD, además, se analiza la oferta que traslada la empresa, resolviendo si la misma se ajusta a sus productos formativos. En dicho caso, se concierta el acuerdo. Asimismo, se lleva a cabo un seguimiento cada tres semanas con el objeto de comprobar si se está produciendo alguna desviación sobre el plan teórico.

En el supuesto de los becarios que procedían de la $\mathrm{CdC}$ se formalizaba un acuerdo entre este organismo y la empresa. A tal efecto, la empresa informa a la CdC sobre lo que necesita y esta analiza si dicha oferta encaja dentro de sus cursos. De ser así, se firma el convenio. Posteriormente, la $\mathrm{CdC}$ ofrece a los estudiantes que se matriculan en cada curso la posibilidad de realizar prácticas en la empresa así seleccionada.

Finalmente, algunos becarios procedían del Servicio Público de Empleo-LANBIDE, a cuyo auspicio habían realizado cursos susceptibles de ser aprovechados en la empresa.

Al margen de estos becarios, la empresa también había seleccionado candidatos entre los curriculum vitae que recibía y a través de ofertas insertas en portales de empleo en la red.

En todos estos casos, el perfil de profesionales que la empresa buscaba para que realizaran prácticas no laborales en la misma no estaba tan relacionado con la titulación que los mismos tuvieran, sino con la vocación y la voluntad de aprender en el campo del marketing.

La actividad desarrollada por los becarios durante la realización de las prácticas se centraba fundamentalmente en el marketing online, dividiéndose esta área en diferentes ramas: a) SEO.SEM: Generar conocimientos para mejorar el posicionamiento web; b) Trade marketing: Diseño de eventos, acciones para captar usuarios. Contrataban a gente por horas para estos eventos (reparto de flyers). Los becarios se dedicaban a ir probando accione de marketing. En ocasiones también repartían flyers cuando fallaba alguno de los trabajadores contratados o había un pico de trabajo para "echar una mano" y, finalmente, c) Telemarketing: llamadas a establecimientos para captar clientes. Si estaban interesados los comerciales que estaban en la calle acudían a los establecimientos. Otros becarios realizaban otras áreas, como la técnica o la comercial.

A cambio de la actividad desarrollada por los becarios, los mismos percibían una beca cuya cuantía era variable y podía oscilar entre los 200 y $600 €$ según los casos. Además, se les proponía un plan de carrera por el cual, cuando terminaban las prácticas, si la empresa se lo podía permitir, se le daba un puesto de trabajo. El plan era la realización de prácticas, y una vez contratado, un sueldo de $16.000 €$ anuales $\mathrm{y}$, posteriormente, $19.000 €$. 
Con carácter general no se abonaban a los becarios ni pluses ni bonus vinculados a cumplimiento de objetivos, pero excepcionalmente se les concedía alguno para premiar algún esfuerzo adicional. Además, se había fijado un sistema de premio para intentar incentivar el trabajo y poner retos.

Los becarios aplicaban en la empresa a nivel práctico la formación recibida en el centro educativo. La empresa asignaba a los becarios unos tutores, consistiendo el sistema de tutorización en "estar muy encima de los becarios al principio, si bien a lo largo de los meses iban siendo proactivos y no habia que estar tan encima de ellos".

Como consecuencia de una actuación inspectora llevada a cabo por la Inspección de Trabajo se levantan a la empresa sendas actas de infracción y liquidación, proponiéndose una sanción de $112.536 €$ por considerarse que los becarios debían mantener con la empresa un vínculo como trabajadores sometidos al régimen común. Ambas actas han sido impugnadas por la empresa.

Ante esta situación, la Tesorería General de la Seguridad Social interpone la correspondiente demanda de procedimiento de oficio en la que se solicita que la relación existente entre los diferentes becarios que han desarrollado sus prácticas no laborales en la empresa demandada sea declarada como una relación laboral común.

Esta demanda es resuelta mediante la sentencia del Juzgado de lo Social núm. 6 de los de Bilbao de 18 de diciembre de 2018, que estima parcialmente dicha demanda y declara la existencia de una relación laboral común entre la empresa demandada y los becarios que habían desarrollado sus prácticas en la misma, a excepción de dos de los mismos.

\subsection{La doctrina contenida en la sentencia del TSJ del País Vasco}

Como era de esperar, la sentencia del Juzgado de lo Social núm. 6 de los de Bilbao de 18 de diciembre de 2018 fue posteriormente recurrida en suplicación tanto por la empresa como por la Tesorería General de la Seguridad Social, habiendo sido resuelto dicho recurso por la STSJ del País Vasco de 14 de mayo de 2019, objeto de este comentario.

Por lo que respecta al recurso interpuesto por la empresa, la misma denuncia la infracción de lo dispuesto en el artículo 1.1 y 1.3.1) ET, en relación con el artículo 2 del Real Decreto 592/2014 y los artículos 1 y 2 del Real Decreto 1543/2011. Frente a esta alegación, el TSJ del País Vasco fija con carácter general los términos del debate, lo 
cual le permitirá resolver después por separado y de forma individualizada cada uno de los supuestos enjuiciados.

En este punto, el TSJ del País Vasco recuerda que la jurisprudencia del Tribunal Supremo se ha pronunciado en diversas ocasiones sobre la cuestión de la diferenciación entre laboralidad o prácticas no laborales, citando al respecto su sentencia de 29 de mayo de 2008, en la que a su vez se citan otras sentencias anteriores, como la de 4 de abril de 2006. A tal efecto, se recuerda que el Alto Tribunal ha indicado que “(...) tanto en la beca como en el contrato de trabajo se da una actividad que es objeto de una remuneración, de ahi la zona fronteriza entre ambas instituciones. De ahi que la clave para distinguir entre beca y contrato de trabajo sea que la finalidad perseguida en la concesión de becas no estriba en beneficiarse de la actividad del becario, sino en la ayuda que se presta en su formación. El rasgo diferencial de la beca como percepción es su finalidad primaria de facilitar el estudio y la formación del becario y no la de apropiarse de los resultados o frutos de su esfuerzo o estudio, obteniendo de ellos una utilidad en beneficio propio, mientras que la relación laboral común no contempla este aspecto formativo y retribuye los servicios prestados por cuenta y a las órdenes del empleador, con independencia de que la realización de los trabajos encomendados puedan tener un efecto de formación por la experiencia, que es inherente a cualquier actividad profesional. De ahi que las labores encomendadas al becario deben estar en consonancia con la finalidad de la beca y, si no es así y las tareas que se le ordena realizar integran los cometidos propios de una categoría profesional, la relación entre las partes será laboral".

En consecuencia, el TSJ del País Vasco, ahora con cita de su propia doctrina contenida en la sentencia de 6 de noviembre de 2018, considera que "el aspecto formativo es tan decisivo e importante por cuanto que es el único factor que a la postre vendría a diferenciar la figura del "becario", del contrato en prácticas, dado el marco educativo en el que nos movemos, y al amparo del artículo 11.1 del ET, el cual viene configurado como una auténtica relación laboral. Por tanto, siendo la excepción el primero y más teniendo en cuenta la presunción incluida en el artículo 8.1, de este mismo texto, ante cualquier duda habrá que inclinarse por la laboralidad".

A lo cual cabe añadir, como ya hiciera la citada STSJ del País Vasco de 6 de noviembre de 2018, que la carga de la prueba sobre que se impartió a los becarios la imprescindible formación y durante todo el tiempo que estuvo vigente la relación recae en la empresa.

Bajo estas premisas, la Sala de lo Social del TSJ del País Vasco procede a analizar los diferentes supuestos impugnados en suplicación. 
En primer lugar, respecto a uno de los becarios que desempeñó su actividad en el Departamento comercial de la empresa, desarrollando prácticas curriculares cuyo objeto era "Apoyo a tareas de marketing. Utilizar eficazmente las tecnologías de la información y los instrumentos informáticos. Saber buscar, analizar y sintetizar información proveniente de diversas fuentes con capacidad crítica, autocrítica y de aprendizaje autónomo", el TSJ del País Vasco constata que la empresa no ha podido acreditar tener ninguna persona con formación reglada en materia de marketing, lo que considera que hubiera sido imprescindible para formar al becario y sin que a la debida formación pueda equivaler lo que se aprenda naturalmente en el desempeño de una actividad, incluso acompañada de otra persona que aparentemente la tutoriza.

A mayor abundamiento, el TSJ del País Vasco recuerda lo previsto en el artículo 9 del Real Decreto 592/2014, que entre los derechos de los estudiantes en prácticas incluye el derecho a tutela, durante el periodo de duración de la correspondiente práctica, por un profesor de la Universidad y por un profesional que preste servicios en la empresa, institución o entidad donde se realice la misma. A lo cual, la norma añade que el tutor designado por la entidad colaboradora deberá ser una persona vinculada a la misma, con experiencia profesional y con los conocimientos necesarios para realizar una tutela efectiva.

En este punto, el Tribunal concluye que la empresa no ha acreditado el cumplimiento de estos requerimientos, al no haber aportado datos sobre persona que tuviera formación reglada en marketing y sin que a ello se oponga que el becario siempre fuera acompañado por un trabajador de la empresa cuando desarrollaba su actividad, puesto que este carecía de la formación necesaria para formar al becario.

En segundo lugar, en relación con los becarios procedentes de la UD, los cuales no habían estado asociados al área comercial, sino a la técnica, desarrollando la actividad como desarrolladores de la App en horario de 6 horas por la mañana, salvo uno de ellos que lo hacía en un horario de tres horas, el TSJ del País Vasco también concluye que dicha actividad no se ajustaba a lo previsto por el Real Decreto 592/2014 ni se ajustaba a los criterios jurisprudenciales expuestos sobre la actividad del becario.

Para llegar a esta conclusión, el TSJ del País Vasco acude nuevamente a la falta de tutorización de los becarios por parte de la empresa, tal y como se desprende de la propia valoración de los becarios que consideran haber asumido una actividad "demasiado responsabilizada", "poco asistida en el plano formativo", "sin recibir instrucciones ni explicaciones ni formación", a lo que algún becario añadía que "se autotutelaba por entender que era él quien sabía del tema". A tal efecto, se considera que pese a existir un tutor, el dueño de la App, ello no empece la escasa relevancia 
formativa de la actividad o de la tutorización. Sin que a ello se oponga que la Universidad no haya reaccionado ante esta realidad, puesto que el criterio sobre el carácter laboral o no de las prácticas no corresponde sino a la administración laboral y, en última instancia, a la jurisdicción.

En tercer lugar, sobre los becarios de la CdC también se constata en uno de los supuestos que no consta la identidad del tutor y, además, no se realizó el informe de prácticas, así como que recibía órdenes de una trabajadora de la empresa y en otro supuesto que no se había recibido formación y que únicamente se mantenían reuniones internas para organizar el trabajo.

De ello deduce el TSJ del País Vasco que, de un lado, falta el presupuesto esencial de este tipo de prácticas, cual es la formación $\mathrm{y}$, de otro, no consta que hubiera en la empresa nadie con capacidad y titulación suficiente para tutorizarlas. A lo que se añade que los horarios eran muy intensos para una situación de prácticas, lo que revelaría un objetivo empresarial más allá de la formación práctica de los becarios en cuestión.

En cuarto lugar, respecto a los becarios de LAMBIDE también se constata que los becarios han desarrollado su actividad dentro del área de marketing, habiendo cursado estudios bajo el auspicio de LAMBIDE, con horarios muy amplios, a lo que cabe añadir la dificultad de que una empresa sin especialistas titulados en marketing para asegurar una formación propia y no meramente profesional a tantas personas, que, por lo demás, manifiestan mayoritariamente no haber recibido formación.

En esta ocasión, el TSJ del País Vasco acude al Real Decreto 1543/2011 para poner de manifiesto que el objetivo de estas prácticas también es el de completar la formación y que ello se desarrollará bajo la dirección y supervisión de un tutor. A lo que se añade que el sistema de tutorías de la empresa consistente en "estar muy encima de los becarios al principio, si bien a lo largo de los meses iban siendo proactivos y no había que estar tan encima de ellos", no expresa en ningún caso cual era la formación brindada ni cuál era el alcance de la preceptiva dirección del tutor.

En quinto lugar, en relación con los becarios procedentes de másteres online, el TSJ del País Vasco recuerda que todos estos becarios fueron reclutados por la empresa porque seguía necesitando cubrir determinadas necesidades en el área de marketing y ya no tenía efectivos suficientes procedentes de las universidades o de LANBIDE. El sistema de reclutamiento de los becarios ha consistido en realizar una oferta de empleo y una vez seleccionados han sido matriculados en una escuela online a cuenta de la empresa. Una vez más, su actividad se ha desarrollado en el área de marketing, en tareas tuteladas formalmente por personal de la empresa que no acredita conocimientos de marketing 
oficiales y con un sistema de tutorías que nuevamente consistía en "estar muy encima de los becarios al principio, si bien a lo largo de los meses iban siendo proactivos y no había que estar tan encima de ellos". Además, sus servicios se han prestado en un horario intenso y desproporcionado con el cometido formativo, bien que coherente con su integración en un área productiva.

En este supuesto, además, el TSJ del País Vasco valora muy especialmente la circunstancia de que los becarios hubieran sido matriculados en másteres on line por cuenta de la empresa. En este punto, recuerda su propia doctrina recogida en sentencia de 6 de noviembre de 2018 según la cual “(...) estimamos que el espíritu de la norma parte de que primero se estudia - artículo 8.1 del Real Decreto- y en el curso de tales estudios se realiza la actividad de becaria-artículos 2.1 y 3 del Real Decreto-; pero no al revés. En este mismo orden de cosas recordemos que los estudios referenciados los inicia siete días después de ser contratada como becaria. Por tanto, ninguna eficacia puede tener el convenio de colaboración suscrito (...) justo el mismo día que inicia la actividad (...); esa coincidencia temporal no es congruente con los artículos 6 y 7 y de nuevo con el artículo 8.1 del Real Decreto".

A ello añade la STSJ de 6 de noviembre de 2018 que "resulta igualmente un tanto atípico, cuando menos a priori, que del coste de tales estudios se haga cargo la propia mercantil (...). A tal fin, ello sería imposible desde la perspectiva que hemos comentado (...) pues solo en el curso de los estudios se puede "conocer" a la empresa colaboradora, pero no antes. En consecuencia, si nos atenemos a las circunstancias que aquí se dan, tal evento no hace sino ratificar que la actuación de la empresa no es conforme a derecho y está buscada a propósito para encubrir una relación laboral".

Volviendo al supuesto enjuiciado, la STSJ del País Vasco de 14 de mayo de 2019 concluye que el hecho de que los másteres online hayan sido por cuenta de la empresa demandada revela que estas personas no se hallaban cursando tales másteres y en el marco de tales estudios hubieran pasado a realizar prácticas externas en la empresa demandada, sino que se reclutaron por la empresa primero y luego se les matriculó en los másteres para simular la formación práctica y ocultar una prestación de servicios auténticamente laboral.

Finalmente, por lo que respecta al recurso interpuesto por la TGSS, en el mismo se reclama, en primer lugar, que también se declare la laboralidad de la relación que vinculaba a otra becaria con la empresa, puesto que, aunque se desconocen las condiciones en que desarrollaba su actividad, se encontraba matriculada en el master online a cuenta de la empresa y que coincidió el inicio del máster con el de sus prácticas en la empresa. Estas meras circunstancias permiten concluir al TSJ del País Vasco que 
nos hallamos ante el reclutamiento de personal para prestar servicios ordinarios, lo que se ha disfrazado o simulado con la realización de un máster, sin que haya ocurrido lo que está en la lógica de la normativa, de que primero se está estudiando y en el marco del programa de estudios se realizan las prácticas externas. Estas valoraciones son consideradas por el Tribunal como suficientes para entender que la relación de la becaria con la empresa debe ser calificada como laboral.

Peor fortuna corre la segunda pretensión invocada por la TGSS respecto a un becario que realizaba sus prácticas externas curriculares en el marco del Doctorado procedente de la UPV/EHU, cuyo objeto era el de "seleccionar variables que sirvan para formular modelos matemáticos que representan de manera eficiente aplicaciones informáticas y que estén dotados de flexibilidad para ser generalizados o adaptados a futuros contextos. Utilizar técnicas estadísticas y de minería de datos para clasificar las causas o variables que tienen mayor influencia en la toma de decisiones y que permitan cuantificar dicha influencia". Las prácticas se desarrollaron en horario global de 1114 horas y con una remuneración asignada de 400 euros/mes.

En este supuesto, sin embargo, el TSJ del País Vasco considera que no tiene datos suficientes para poder declarar el carácter laboral de la relación que vincula a la empresa con el becario, puesto que no resulta asimilable al resto de quienes han prestado las prácticas en el área de marketing al no constar respecto a este becario ningún otro extremo.

\section{El siempre difícil deslinde entre las prácticas no laborales de los estudiantes universitarios y titulados recientes y la relación laboral: la correcta tutorización de las prácticas como factor clave.}

A pesar de la proclamación de no laboralidad de las prácticas no laborales de los estudiantes universitarios y los titulados recientes, en la práctica no siempre resulta clara la línea divisoria entre aquellas prácticas acordes con la legalidad y aquellas otras prácticas fraudulentas que podrían estar encubriendo una auténtica relación laboral ${ }^{17}$. En este punto, resulta evidente que las prácticas no laborales, cuando las mismas son retribuidas económicamente, pueden comportar problemas de delimitación con el contrato de trabajo, que recoge la prestación voluntaria por parte del trabajador de servicios retribuidos por cuenta ajena y dentro del ámbito de organización y dirección

\footnotetext{
${ }^{17}$ En la misma dirección, en relación con las prácticas no laborales de los estudiantes universitarios, BAVIERA PUIG, I. "Las prácticas formativas para estudiantes universitarios en el EEES", Aranzadi Social, núm. 2, 2011, indica que "pese al definido marco normativo se trata de una figura donde no siempre está clara la linea divisoria entre la legalidad y el fraude, es decir, si realmente nos encontramos ante una auténtica formación o por el contrario se elude la normativa laboral”.
} 
del empresario, ya que, a priori, toda relación en la que se produzca entre las partes un intercambio de prestación de servicios y remuneración de los mismos puede ser calificada como laboral de conformidad con la amplitud que de tal concepto se desprende del artículo 1.1 ET.

En consecuencia, siendo el carácter no laboral la característica esencial de las prácticas no laborales de los estudiantes universitarios y titulados recientes, la principal cuestión que las mismas plantean debe ser necesariamente la delimitación entre la prestación de servicios que se desarrolla en el marco de estas prácticas no laborales y la prestación de servicios propia de la relación laboral. A tal efecto, en las diferentes regulaciones de las prácticas no laborales se echa de menos que se lleve a cabo un deslinde conceptual entre las prácticas que se regulan y la prestación de servicios laboral. Pese a ello, en este punto resultan plenamente aplicables los tradicionales criterios de distinción elaborados por la doctrina y la jurisprudencia entre las becas y el contrato de trabajo ${ }^{18}$. Veamos, por tanto, cuales son estos criterios.

La distinción entre las becas y el contrato de trabajo se fundamenta esencialmente en la distinta finalidad que se persigue con cada una de estas figuras. En esta dirección, el objetivo del contrato de trabajo es la obtención de un valor productivo inmediato, mientras que la beca, por el contrario, o bien no busca esa finalidad productiva en absoluto, o bien sólo la busca relativamente, de manera aplazada o diferida al futuro, siendo el elemento predominante el aumento de bagaje cultural, intelectual o técnico, es decir, la formación del becario. En definitiva, mientras que a través del contrato de trabajo la persona "da", en la beca la persona "recibe"19.

Por tanto, las becas tienen como dato calificativo más relevante que el becario adquiera una formación mediante la realización de una actividad cuyo coste económico lo soporta la entidad que financia la beca, lo que comporta la inexigencia al becario de una prestación que revirtiendo directamente en utilidad o beneficio de la entidad que otorga la beca, predomine sobre su formación ${ }^{20}$, sin perjuicio de que en ocasiones las

\footnotetext{
18 En esta misma dirección, SÁNCHEZ-RodAs NAVARRO, C. "Formas no laborales de inserción de los jóvenes en el mercado de trabajo”, en Monereo PÉrez, J.L. (Coord.) Retos del Derecho del Trabajo frente al desempleo juvenil, Consejo Andaluz de Relaciones Laborales, Sevilla, 2014, pág. 210, mantiene que "la jurisprudencia sobre becas es aplicable, mutatits mutandi, a las prácticas no laborales".

19 FERNÁNDEZ MÁRQUEZ, O. "Nuevas normas sobre los becarios y el personal sanitario residente: otra ocasión para la reflexión sobre el "trabajo formativo"”, Temas Laborales, núm. 74, 2004, pág. 38. Ello no impide, sin embargo, que la relación laboral pueda ser también un marco adecuado para la obtención de formación. Vid. también sobre esta cuestión FERNÁNDEZ MÁRQUEZ, O. "La relación laboral como ámbito del trabajo formativo", Revista Española de Derecho del Trabajo, núm. 124, 2004.

${ }^{20}$ Vid. STS de 7 de julio de 1998 (RJ $\backslash 1999 \backslash 6161$ ), así como la jurisprudencia citada en la misma. En la citada resolución se establece que para que pueda hablarse de beca es necesario que su finalidad, real y
} 
actividades desarrolladas por el mismo pueden fructificar en la realización de diversas tareas, que en todo caso no se realizan como contraprestación, sino como aportación de un mérito para hacerse acreedor de la beca y disminuir así la carga de onerosidad que la beca representa ${ }^{21}$.

En otros términos, la jurisprudencia ha puesto de manifiesto que "conceptualmente las becas son en general retribuciones dinerarias o en especie orientadas a posibilitar el estudio y formación del becario, aunque también es cierto que este estudio y formación puede en no pocas ocasiones fructificar en la realización de una obra, pero siempre sin olvidar que estas producciones o la formación conseguida, en los becarios, nunca se incorpora a la ordenación productiva de la institución que otorga la beca. Por ello, si bien el perceptor de una beca realiza una actividad que podría ser entendida como trabajo y percibe una remuneración en atención a la misma, por el contrario aquel que concede la beca y la hace efectiva no puede confundirse nunca con la condición propia de empresario ya que no incorpora el trabajo del becario a su patrimonio, circunstancia esencial a la figura del empresario, cuya actividad si bien puede carecer de ánimo de lucro, lo que siempre es subjetivo, no carece nunca de lo que en este aspecto puede denominarse sentido de lucro en la actividad que ejerce"22.

En definitiva, la distinción entre beca y relación laboral se apoya en la determinación de cual es el interés o beneficio principal que se satisface con la ayuda y con los servicios que como consecuencia de la misma se prestan, si el de los becarios o el de la propia entidad convocante de la ayuda o receptora del becario $^{23}$, de modo que la finalidad

efectiva, no simulada, sea la del "perfeccionamiento profesional" del becario, finalidad que debe estar, si no de forma exclusiva, sí con cierta entidad y prevalencia.

${ }^{21} \mathrm{La}$ compatibilidad de las becas con la prestación por parte del becario de servicios u obras en beneficio de la entidad otorgante de la beca ha sido admitida de forma unánime por la jurisprudencia, así, por ejemplo, se admite que las becas fructifiquen en "la realización de una tarea" (STSJ del País Vasco de 21 de junio de 1993 (AS\1993\2873); "la realización de una obra (STS 13 de junio de 1988 (RJ $1988 \backslash 5270$ ); "la realización de unos servicios" (STS de 13 d abril de 1989 (RJ\1989\2967); "la ejecución de trabajos varios" (STSJ de Madrid de 1 de febrero de 1990 (AS\1990\694); etcétera.

${ }^{22}$ Vid. STSJ de Andalucía (Granada) de 26 de septiembre de 2001 (AS\2001 2981 ).

${ }^{23}$ MARTín VALVERDE, A. "Fronteras y "zonas grises" del Derecho del Trabajo en la jurisprudencia actual (1980-2001)”, Revista del Ministerio de Trabajo y Asuntos Sociales, núm. 38, 2003, se refiere al "criterio de prevalencia". Vid. también, ORTEGa LOZANO, P.G. "La delgada línea divisoria entre una relación laboral asalariada y la remuneración o contraprestación económica del becario como zona gris del Derecho del Trabajo", Revista Española de Derecho del Trabajo, núm. 218, 2019, págs. 87 a 126 y POQUET CATALÀ, R. "Zona gris entre la relación de becario y la relación laboral común y protección social actual”, Revista Española de Derecho del Trabajo, núm. 192, 2016, págs. 47 a 76. 
perseguida se configura como "el único e inseguro elemento diferenciador" entre la beca y el contrato de trabajo ${ }^{24}$.

A partir de estas premisas pueden establecerse diferentes criterios que nos permitirán determinar si la utilidad o beneficio principal de la actividad desarrollada por el becario repercute en éste o, por el contrario, la obtiene la entidad convocante de las ayudas o receptora del becario, dándose cumplimiento así al presupuesto sustantivo de la ajenidad $^{25}$.

Un primer criterio lo constituye la apreciación o no de supeditación o subordinación de la formación recibida por el becario al trabajo que realiza. Este requisito constituye a nuestro entender el elemento esencial que permite calificar al becario, ya que en la medida en que las actividades desarrolladas por el mismo predominen sobre su formación, no será éste, sino la entidad convocante de la ayuda o receptora del mismo, quien obtenga el interés o beneficio principal de su actividad. Por tanto, las actividades a realizar por el becario tienen que realizarse de forma que resulten compatibles con el aprovechamiento del propio becario y siempre subordinadas a sus propias obligaciones formativas $^{26}$.

Un segundo criterio válido para determinar quien obtiene la utilidad de los servicios prestados por el becario lo constituye la existencia de identidad entre las tareas encomendadas al becario y las funciones realizadas por el resto de trabajadores de la entidad que otorga la ayuda o, en su caso, por la entidad receptora del becario, porque aunque no se realicen exactamente las mismas tareas, en la medida en que el trabajo desempeñado por el becario sea coincidente con las funciones ejecutadas por los trabajadores de la entidad convocante de la ayuda y/o receptora del mismo, hay más argumentos para afirmar que la actividad desarrollada por el mismo sea considerada como laboral ${ }^{27}$, especialmente si se trata de trabajos esenciales, necesarios e

\footnotetext{
${ }^{24}$ Vid. también, STSJ de Madrid de 1 de febrero de 1990 (AS\1990\694). El carácter extremadamente casuístico de esta materia supone que, aunque se pueden extraer de la doctrina y jurisprudencia ciertos parámetros definidores o caracterizadores de una y otra figura en términos generales, es preciso acoplarlos a cada caso concreto y específico objeto de resolución (STSJ de Castilla-La Mancha de 13 de noviembre de 1998 (AS\1998\4515).

${ }^{25}$ Vid. SSTS de 4 de abril de 2006 (RJ 2006/2325) y de 28 de mayo de 2008 (RJ/2008\5130).

${ }^{26}$ FERNÁNDEZ MÁRQUEZ, O. "Nuevas normas sobre los becarios..." cit., págs. 32 y 33, incluye este criterio entre los factores determinantes de la existencia de beca, considerando determinante de la falsedad de una beca la asignación al becario de "tareas estériles a efectos de su formación", "trabajos distintos de los definidos como trabajo formativo en el marco de la beca de que se trate", "trabajos con asunción de responsabilidades excesivas o cuya realización presupone la plena formación de quien los realiza", etcétera.

${ }^{27}$ Vid. MarTín VALVERDE, A. "Beca de estudios técnico-prácticos con opción de reingreso en una entidad bancaria”, Revista de Política Social, núm. 99, 1973, pág. 263. Vid., entre otras, STSJ de Aragón
} 
imprescindibles para el normal funcionamiento de quien concede la ayuda ${ }^{28}$. Por el contrario, la actividad del becario debe responder a la finalidad de su perfeccionamiento y no ser utilizada por la entidad convocante de la beca y/o receptora del becario para paliar sus necesidades, de manera que aunque el becario ocupe un verdadero puesto de trabajo, su actividad ha de ser periférica, no inmediatamente necesaria a la empresa en que se realiza el período de formación en régimen de beca ${ }^{29}$. En definitiva, para que se trate de una auténtica beca, debe existir una especialidad de las funciones o tareas que diferencie a los becarios de los trabajadores ordinarios de la empresa en el que los mismos desarrollan su actividad ${ }^{30}$.

de 26 de junio de 1999 (AS\1999\1883) y STSJ Madrid de 14 de octubre de 1994 (AS\1994\4103). Sin embargo, no se atribuyen estos mismos efectos cuando no hay identidad entre las tareas realizadas durante la vigencia de la beca y las realizadas con posterioridad como consecuencia de una relación laboral, puesto que puede "evitarse la concurrencia de ciertas tareas comunes a la condición de becaria y trabajadora" (STSJ Cataluña de 4 de septiembre de 1996 (AS\199613634).

${ }^{28}$ Vid. FERNÁNDEZ MÁRQUEZ, O. "Nuevas normas sobre los becarios..." cit., pág. 36.

${ }^{29}$ En esta dirección, la STSJ de Andalucía (Granada) de 26 de septiembre de 2001 (AS\200112981), reconoce el carácter laboral de la prestación de servicios entre un becario de investigación y la Universidad de Granada, por los siguientes motivos: "su actividad se incorporaba esencialmente a la actividad de la unidad", "desde que se fue el actor no se puede atender el funcionamiento del servicio", "por el hecho de que ha venido realizando unas funciones que sino hubieren sido por él realizadas tendrían que encomendarse a personal laboral", "el actor venia cumpliendo con el horario habitual de la unidad, disfrutando asimismo de las vacaciones en agosto como el resto de los que prestaban sus servicios en la unidad", "realizaba los contenidos propios de la actividad de la unidad", etcétera. La STSJ de Madrid de 2 de febrero de 2001 (AS\2001\1246) admite una relación laboral entre dos becarias de investigación y la Universidad Autónoma de Madrid porque ambas habían venido "realizando trabajos propios de la administración jurídica, bajo la dependencia directa de los letrados adscritos a la misma y sometidas a horario, y acometiendo de manera principal tareas ajenas al objeto de la beca y a su proceso de formación, con independencia de poder haber realizado en algún momento alguna función relacionada con el objetivo y función de la beca, si bien de forma "mínima" (...) al no constar que en tales casos contase tal actividad con la supervisión o dependencia de un profesor o departamento docente". La STSJ de Madrid de 26 de octubre de 2000 (AS\2000\4322), también considera laboral una beca para la investigación porque la becaria, junto con la participación en diversos proyectos "además ha venido efectuando trabajos de colaboración con la investigación, realizando encargos de compañeros, ha llevado a cabo la labor administrativa, ha introducido datos en el ordenador y ha copiado documentos del Director (...)".

${ }^{30}$ Vid. AhUMADA VILlalbA, B., "La beca de formación práctica con prestación de servicios", Relaciones Laborales, 1999-I. La autora considera al respecto que no estaremos en presencia de una beca sino se pone de manifiesto la diferencia de cometido, dedicación, horario o jerarquización entre la realización de las labores propias de la beca y las de otros titulados no sujetos al sistema de becas. En la misma dirección, GOÑ SEIN, J.L., "La inserción profesional de los jóvenes en la empresa a través de las becas", Relaciones Laborales, 1986-II, considera que "en el caso de que el servicio prestado por el becario resulte ser permanente y esencial para el funcionamiento del centro o empresa; si responde a las necesidades permanentes de la misma y su actividad es normal, habitual y continuada, la concesión de la beca será a todas luces una simulación de un contrato". 
Junto con estos criterios que deben permitir determinar quien obtiene el interés o beneficio principal de la beca y, por tanto, determinar si concurre o no el requisito de la ajenidad, también debe analizarse si en el desarrollo de su actividad, el becario se encuentra sometido a una dependencia meramente académica o a una auténtica dependencia laboral ${ }^{31}$, dando cumplimiento de este modo al segundo elemento definidor de la relación laboral que contiene el artículo 1.1 $\mathrm{ET}^{32}$.

El análisis de la dependencia, entendida en su acepción actual, es decir, como la exigencia de que el trabajo se realice bajo la dirección del empresario, pero no como subordinación rigurosa y absoluta del trabajador, sino como inclusión en el círculo rector y disciplinario de una unidad empresarial, comporta distinguir, en primer lugar, si los becarios sólo siguen las instrucciones y consejos orientativos de la persona encargada de su formación o si, por el contrario, se integran en el ámbito organizativo de la entidad concedente de la ayuda y/o receptora del becario, bajo su dirección y dependencia y, en segundo lugar, si la entidad convocante de la ayuda y/o receptora del becario está controlando y sancionando la actividad del mismo o si, por el contrario, la misma únicamente le está dirigiendo y sancionando sus incumplimientos, en aras a garantizar el correcto desarrollo de su formación.

Para poder calificar al beneficiario de la beca como un auténtico becario, el mismo no debería adaptarse a una determinada organización de trabajo que le es ajena, sino que debería ser el centro receptor del mismo el que se encontrara obligado a funcionalizar su organización a los fines de aplicación y perfeccionamiento de la formación. Asimismo, para poder hablar de becas debería haber ausencia de subordinación jurídica, de modo

\footnotetext{
${ }^{31}$ Sobre la distinción entre dependencia laboral y dependencia académica vid. SELMA PeÑalVA, A., "Los becarios aparentes. Comentario a la STSJ del País Vasco, de 18 de marzo de 2003 (AS 2003, 2567), Aranzadi Social, núm. 14, 2003, pág. 58 y Selma PeÑalva, A., Los límites del contrato de trabajo en la jurisprudencia española, Tirant lo Blanch, Valencia, 2007, págs. 363-364. La autora considera al respecto que "durante el desempeño normal y legítimo de una auténtica beca, el beneficiario manifiesta, respecto a la organización en la que se integra (que puede coincidir o no con el sujeto convocante de la beca), una relación de dependencia muy intensa pero muy distinta a la laboral. Es una relación formativa con la organización en cuestión y en particular con el sujeto que normalmente se nombra como "tutor", "director", "supervisor" del trabajo del becario. En el caso de que se haya dado lugar a una auténtica beca la finalidad de las instrucciones recibidas, será sólo orientar la formación del sujeto para que sea lo más completa posible; en cambio, se apreciará fraude si la intensidad de la organización y control de la prestación del sujeto formalmente adjudicatario de la beca llega al extremo de adoptar perfiles de dependencia laboral".

32 Vid. entre otras muchas, STS de 26 de octubre de 2015 (RJ\2015\5240), STSJ del País Vasco de 18 de marzo de 2003 (AS\2003\2567), STSJ de Andalucía (Sevilla) de 19 de julio de 2004 (AS\2005\2425), STSJ de la Comunidad Valenciana de 20 de julio de 2010 (AS\201012602), STSJ de Madrid de 22 de junio de 2011 (AS\201112373), STSJ de Andalucía (Granada) de 11 de julio de 2019 (JUR\2019\59917), etcétera.
} 
que el becario pudiera rehusar libremente cualquier manifestación del poder de dirección, aunque deba someterse a las instrucciones o indicaciones necesarias para el correcto desarrollo de la actividad de formación, sobre todo a aquellas que provengan de sus tutores técnicos. Finalmente, en las becas, la entidad receptora del becario no sólo debería soportar todos sus errores e incapacidades, sino que además debería corregirlos y ayudarlo a mejorar en la realización de la actividad de que se trate, sin que se le pueda exigir que actúe de acuerdo a criterios de productividad ${ }^{33}$. En caso de no cumplirse con todas estas exigencias, no se tratará de una auténtica beca, sino de una relación laboral, por concurrir la nota de dependencia prevista por la legislación laboral.

En definitiva, en el caso de las actividades realizadas bajo la cobertura de las prácticas no laborales, habrá que examinar el contenido concreto de la relación mantenida entre empresa y quien realiza las prácticas, para comprobar si efectivamente tales actividades responden a la finalidad formativa propia de las citadas prácticas no laborales, o si, por el contrario, dichas prácticas encubren una auténtica relación laboral en la que se encuentran presentes las notas de ajenidad y dependencia.

En este contexto, no han faltado resoluciones judiciales que al abordar las prácticas no laborales de los estudiantes universitarios y titulados recientes han concluido que dichas prácticas en realidad estaban encubriendo una relación laboral ${ }^{34}$. Con carácter general, dichas resoluciones vienen a considerar que las prácticas realizadas por los estudiantes universitarios o titulados recientes no tenían por objeto reforzar la formación de éstos para preparar su incorporación futura al trabajo, sino obtener por parte de la entidad en la que se desarrollaban mano de obra barata y al margen de las normas que regulan el mercado laboral, sin perjuicio de que los estudiantes o titulados recientes en prácticas hayan podido adquirir cierta experiencia en el desempeño del trabajo encomendado por cuanto que ello es inherente a toda prestación de servicios que tenga una cierta prolongación en el tiempo.

\footnotetext{
${ }^{33}$ Vid. Ahumada VilLaLba, B., "La beca de formación práctica..." cit.

${ }^{34}$ Un análisis de diferentes supuestos en MORENO GeNÉ, J., "La nueva regulación de las prácticas académicas externas de los estudiantes universitarios: la potenciación de la finalidad formativa y de mejora de la empleabilidad", Revista de Trabajo y Seguridad Social. CEF, núm. 349, 2012, págs. 14-17 y MoRENo GeNÉ, J. "El recurso fraudulento a las prácticas no laborales en empresas previstas en el Real Decreto 1543/2011 y sus efectos. A propósito de la STSJ de Asturias de 20 de septiembre de 2016", Revista General de Derecho del Trabajo y de la Seguridad Social, núm. 46, 2017. Vid. también, BAVIERA PUIG, I. "Las prácticas formativas para universitarios..." cit., FERNÁNDEZ ORRICO, F.J., "La Seguridad Social de quienes participan en programas de formación..." cit., GuINDO MORALES, S. y ORTEGA LOZANO, P.G., "El régimen jurídico de seguridad social de las prácticas remuneradas y de las prácticas no remuneradas: la nueva obligación de cotizar en ambos regímenes como sujetos asimilados a trabajadores por cuenta ajena", Revista General de Derecho del Trabajo y de la Seguridad Social, núm. 52, 2019, pág. 362 y SÁNCHEZ-RodAs NAVARRO, C., "Formas no laborales de inserción de los jóvenes..." cit., págs. 22 y 23.
} 
En esta línea cabe incardinar la sentencia la STSJ del País Vasco de 14 de mayo de 2019 objeto de este comentario que, a la hora de diferenciar entre prácticas no laborales y relación laboral, se apoya, como no puede ser de otro modo, en la imprescindible formación que necesariamente debe recibir quien realiza las prácticas no laborales. En este punto, es donde la resolución analizada lleva a cabo su principal aportación al respecto, al conceder una relevancia determinante a la correcta tutorización por parte de la empresa de quienes desarrollan en la misma sus prácticas no laborales. A tal efecto, no se admite una tutorización meramente formal, sino que se exige que la misma sea realmente efectiva. Vale la pena, por tanto, ver como la normativa reguladora de las prácticas no laborales regula esta materia.

Como ya se acaba de indicar, uno de los elementos definidores de las prácticas académicas externas de los estudiantes universitarios y fundamental a la hora de diferenciarlas de una relación laboral, consiste en que la actividad desarrollada por el estudiante en prácticas debe estar sometida a tutela, de modo que durante toda la duración de las prácticas debe existir un seguimiento y control sobre el aprovechamiento de las mismas por parte del tutor, que a tal efecto deberá dar al estudiante o titulado reciente todas las indicaciones e instrucciones necesarias para el correcto desarrollo de la actividad efectuada y, por tanto, de su formación.

La importancia del papel del tutor para garantizar el carácter formativo de las prácticas no laborales y, en consecuencia, para diferenciar estas prácticas de las prestaciones de servicios laborales, ha llevado a afirmar que "una ineficiente tutorización académica (y un silencio del alumno, deseoso de poder engancharse al mercado de trabajo en esa empresa a través de dicha práctica) permitirá que se desfigure bajo la apariencia de una "beca", "bolsa o ayuda a estudios", un contrato de trabajo y, en consecuencia con ello, dará lugar a un "resultado prohibido por el ordenamiento jurídico o contrario a él"35.

Dando cumplimiento a esta exigencia, el artículo 10.1 del Real Decreto 592/2014 establece que "para la realización de las prácticas externas los estudiantes contarán con un tutor de la entidad colaboradora y un tutor académico de la universidad". Por tanto, en el desarrollo de las prácticas académicas externas la normativa prevé la presencia de dos tutores distintos, uno de la entidad colaboradora y otro de la universidad, habiéndose procedido a regular por primera vez de un modo muy extenso los derechos, facultades y deberes de estos tutores, si bien, en este momento nos limitaremos en este estudio a analizar únicamente el régimen jurídico de los tutores de la entidad colaboradora.

\footnotetext{
${ }^{35}$ Vid. GoÑI SEIN, J.L., “La inserción profesional...” cit., págs. 408 y ss.
} 
El decisivo papel que corresponde desempeñar a los tutores de la entidad colaboradora exige que los mismos reúnan determinadas características ${ }^{36}$. Para garantizar la idoneidad de estos tutores, el artículo 10 del Real Decreto 592/2014 establece los requisitos que los mismos deben reunir. A tal efecto, el artículo 10.2 del Real Decreto $592 / 2014$ establece que "el tutor designado por la entidad colaboradora deberá ser una persona vinculada a la misma, con experiencia profesional y con los conocimientos necesarios para realizar la tutela". En consecuencia, la condición primordial que debe satisfacer el tutor de la entidad colaboradora es que siendo una persona vinculada a la misma, reúna la experiencia y los conocimientos profesionales necesarios para desarrollar de un modo satisfactorio su función, es decir, realizar el seguimiento y control sobre el aprovechamiento de las prácticas, realizando al estudiante todas las indicaciones e instrucciones necesarias para el correcto desarrollo de las mismas y, por extensión, para que se satisfaga el objetivo de su formación.

Una vez identificados los tutores de la entidad colaboradora, el Real Decreto 592/2014 enumera los deberes que a los mismos les corresponden, los cuales se configuran como la garantía última del carácter formativo de estas prácticas ${ }^{37}$. Como se desprende de la lectura de dicho precepto, el Real Decreto 592/2014 contiene un listado exhaustivo de deberes que deben garantizar que durante toda la duración de las prácticas el tutor lleve

36 DuQue GonzÁlez, M., Becas y becarios: camino de su regulación laboral, Lex Nova-Thomson Reuters, Valladolid, 2012, pág. 234, en relación con el anterior Real Decreto 1707/2011 señalaba que los tutores "deben reunir una serie de requisitos que garanticen su profesionalidad y su dedicación a las tareas de tutoría, en un intento de que esta figura no sea meramente testimonial sino que de forma efectiva se convierta en un instrumento de formación práctica sobre el terreno que beneficie al estudiante".

37 A tal efecto, de conformidad con el artículo 11.2 del Real Decreto 592/2014, el tutor de la entidad colaboradora tiene los siguientes deberes: a) Acoger al estudiante y organizar la actividad a desarrollar con arreglo a lo establecido en el proyecto formativo; b) Supervisar sus actividades, orientar y controlar el desarrollo de la práctica con una relación basada en el respeto mutuo y el compromiso con el aprendizaje; c) Informar al estudiante de la organización y funcionamiento de la entidad y de la normativa de interés, especialmente la relativa a la seguridad y riesgos laborales; d) Coordinar con el tutor académico de la universidad el desarrollo de las actividades establecidas en el convenio de cooperación educativa, incluyendo aquellas modificaciones del plan formativo que puedan ser necesarias para el normal desarrollo de la práctica, así como la comunicación y resolución de posibles incidencias que pudieran surgir en el desarrollo de la misma y el control de los permisos para la realización de exámenes; e) Emitir el informe final y, en su caso, el informe intermedio de las prácticas; f) Proporcionar la formación complementaria que precise el estudiante para la realización de las prácticas; g) Facilitar y estimular la aportación de propuestas de innovación, mejora y emprendimiento por parte del estudiante; h) Facilitar al tutor académico de la universidad el acceso a la entidad para el cumplimiento de los fines propios de su función; i) Guardar confidencialidad en relación con cualquier información que conozca del estudiante como consecuencia de su actividad como tutor; y, finalmente, j) Prestar ayuda y asistencia al estudiante, durante su estancia en la entidad, para la resolución de aquellas cuestiones de carácter profesional que puede necesitar en el desempeño de las actividades que realiza en la misma. 
a cabo un adecuado seguimiento y control sobre el aprovechamiento de las mismas por parte del estudiante que las realiza, realizándose al respecto todas las indicaciones e instrucciones necesarias para el correcto desarrollo de la actividad efectuada y, por tanto, de la formación de quien la realiza. Con esta finalidad resultan especialmente significativos los deberes previstos en la norma de "acoger al estudiante y organizar la actividad a desarrollar con arreglo a lo establecido en el proyecto formativo", "supervisar sus actividades, orientar y controlar el desarrollo de la práctica con una relación basada en el respeto mutuo y el compromiso con el aprendizaje" y, finalmente, "prestar ayuda y asistencia al estudiante, durante su estancia en la entidad, para la resolución de aquellas cuestiones de carácter profesional que pueda necesitar en el desempeño de las actividades que realiza en la misma".

De un modo mucho más parco, el artículo 3.3. del Real Decreto 1543/2011 establece que el acuerdo que deben suscribir la empresa y la persona joven que va a desarrollar las prácticas no laborales desarrolladas en el marco de dicha norma también debe especificar el sistema de tutorías, no en vano, en estos supuestos, las prácticas también se desarrollan bajo la dirección y supervisión de un tutor. Sin embargo, ante la importancia que debe tener esta figura para el correcto desarrollo de las prácticas se echa de menos una mayor regulación de la misma, especialmente por lo que respecta a los requisitos que debe cumplir el tutor y cuáles son sus obligaciones en relación con la persona que desarrolla las prácticas no laborales. En este punto, contrasta la escasa atención que se concede a esta figura en el Real Decreto 1543/2011 frente a la regulación detallada de la misma que se contiene en la normativa reguladora de las prácticas académicas externas de los estudiantes universitarios que se acaba de exponer.

Pese a esta parquedad en la regulación de estas prácticas no laborales, no cabe duda que el plan de formación de quienes desarrollan estas prácticas debe estar sometido a tutela. En este sentido, el artículo 4.4 del Real Decreto 1543/2011 indica que en el programa de prácticas no laborales deberá hacerse indicación del sistema de tutorías y el artículo 3.2 de la misma norma insiste en esta cuestión cuando indica que las prácticas se desarrollarán bajo la dirección de un tutor. Corresponde a este tutor dirigir y ordenar la actividad de quienes realizan las prácticas no laborales, para lo cual resulta indispensable que se trate de un trabajador vinculado a la empresa, con experiencia profesional y con los conocimientos necesarios para realizar una tutela efectiva.

Asimismo, debe existir un seguimiento y control sobre el aprovechamiento del programa de formación, de modo que durante toda la vigencia del mismo deben darse por parte del tutor las indicaciones e instrucciones necesarias para el correcto desarrollo de las prácticas efectuadas $\mathrm{y}$, por tanto, para la mejora de la formación de quien las realiza. A tal efecto, el artículo 4.4 del Real Decreto 1543/2011 indica que en el 
programa de prácticas no laborales deberá hacerse indicación del "sistema de evaluación". En consecuencia, tanto el tutor como la empresa en que se desarrollan las prácticas deberá establecer los sistemas de evaluación necesarios para garantizar el correcto desarrollo del programa de prácticas no laborales.

Una vez expuesto el papel que deben desempeñar los tutores en las prácticas no laborales desarrolladas por los estudiantes universitarios y titulados recientes no cabe duda que el mismo no se cumple en el supuesto enjuiciado por la STSJ de 14 de mayo de 2019, no en vano, del relato de hechos probados se desprende que, o bien, no se había asignado un tutor, o bien, el mismo no disponía de la cualificación profesional adecuada, o bien, el mismo no había ejercido las funciones de tutorización que le correspondían.

Ante esta situación, el TSJ del País Vasco no tenía otra opción, como así ha sucedido, que declarar el carácter fraudulento de las prácticas no laborales realizadas por los becarios, a la sazón estudiantes universitarios y titulados recientes, en la empresa demandada, no en vano, la falta de tutorización de los mismos permite constatar una ausencia total del elemento formativo que necesariamente debe predominar durante la realización de las prácticas, en favor de un claro predominio del aprovechamiento que obtiene la empresa del trabajo desempañado por los becarios durante la realización de las mismas.

Por el contrario, la correcta tutorización de los estudiantes y titulados recientes que desarrollan sus prácticas no laborales ha sido considerado como uno de los principales criterios que avalan el carácter formativo de estas prácticas y, a la sazón, su naturaleza no laboral. A tal efecto, la STSJ de Madrid de 21 de septiembre de 2017 considera ajustada a derecho las prácticas no laborales desarrolladas en una universidad pública al considerar que "la demandante ejerció las actividades expresamente relacionadas en las bases para la convocatoria, selección y adjudicación de la beca de que disfrutó en la Universidad (...) Estas actividades las realizó bajo la supervisión de un tutor, estaban dentro de la actividad profesional de los estudios que realizaba de Magisterio que desde luego incluye la orientación a los alumnos sobre las prácticas, los cursos de formación continua; no formaban parte de la actividad esencial de la Universidad que es la de impartir clases y facilitar formación académica a los alumnos, y no suponía ningún beneficio para la Entidad sino que eran los estudiantes los que se aprovechaban y disfrutaban de la atención y orientación que les prestaba para que pudieran solicitar prácticas y formación continua" ${ }^{38}$. En parecidos términos, la STSJ de Madrid de 20 de febrero de 2017 concluye que la actividad de los estudiantes en prácticas también desarrollada en otro centro universitario "no era productiva, sino formativa, bajo la

38 JUR $2017 \backslash 256378$. 
tutela de un supervisor que controlaba los trabajos encomendados al estudiante becario" 39 .

En todo caso, más allá de proceder en estos supuestos a la necesaria sanción por la falta o deficiente tutorización en las prácticas no laborales que desarrollan los estudiantes universitarios y los titulados recientes, mediante la conversión de las mismas en auténticas relaciones laborales, debe abogarse por una actuación preventiva que debe consistir en un mayor reconocimiento y valoración de la función de los tutores en las prácticas no laborales, especialmente, los de la entidad colaboradora. Con ello, sin lugar a dudas, se contribuiría a potenciar la figura del tutor y a asegurar un buen ejercicio de la tutorización de las prácticas no laborales y, al mismo tiempo, a delimitar mejor las prácticas no laborales de lo que deben ser auténticas relaciones laborales. En este sentido, si realmente quieren valorizarse las prácticas no laborales de los estudiantes universitarios y titulados recientes, la función del tutor no puede dejarse en manos del voluntarismo de los mismos, sino que debe reconocerse de un modo significativo esta actividad.

A tal efecto, aunque no es una cuestión que deba desarrollarse en la normativa educativa, sino en la laboral y, en especial, en los convenios colectivos, sería conveniente que se contemplara una especie de "crédito horario" o el carácter retribuido de las tareas de tutorización para compensar el tiempo que el tutor de la entidad colaboradora tenga que dedicar al correcto desempeño de su labor, puesto que actualmente las tareas que le corresponden como tutor se solapan a sus específicas tareas laborales. En este punto, tal vez podrían extenderse a los tutores de prácticas académicas externas las previsiones contenidas en algún convenio colectivo en relación con los tutores previstos en el contrato para la formación y el aprendizaje. A tal efecto, se pueden identificar algunas prácticas negociadoras que se dirigen a compensar las tareas formativas del tutor previsto en el contrato para la formación y el aprendizaje a través de la creación de complementos salariales específicos ${ }^{40}$.

En esta dirección, también sería conveniente que la negociación colectiva abordara de forma conjunta las tutorías para los contratos formativos y las prácticas no laborales estableciéndose al respecto que las empresas deben garantizar la existencia de un proceso tutorial, realizado por una persona capacitada para ello, que facilite el proceso de aprendizaje en el puesto de trabajo. En esta dirección, la disposición transitoria primera del Convenio colectivo de la Industria del Calzado, bajo el epígrafe de "Formación profesional", establece entre las funciones de la Comisión Paritaria de

\footnotetext{
39 JUR\2017\89803.

${ }^{40}$ Vid. MUÑOZ RUIZ, A.B., "Buenas prácticas relativas a la formación profesional dual en la negociación colectiva", Revista de Información Laboral, núm. 4, 2014.
} 
Formación el “(...) Seguimiento y tutela de los derechos de las personas con contratos de formación y de quienes realizan prácticas laborales, que incluyan formación en centros de trabajo de la formación profesional reglada, las prácticas en empresas que realizan los desempleados/desempleadas participantes en cursos con un módulo de formación en centros de trabajo y las prácticas no laborales que realizan las personas becarias o estudiantes de los últimos cursos universitarios" "41. Aún de un modo más preciso, el artículo 53 del Convenio colectivo estatal del sector laboral de la restauración colectiva, bajo el epígrafe de contratos con finalidad formativa, incluye junto a los contratos formativos (de formación y aprendizaje y en prácticas), las prácticas profesionales no laborales, la formación en centros de trabajo de desempleados/as y los becarios/as así como cualquier modalidad similar, estableciéndose en todos estos supuestos que para asegurar la finalidad de este tipo de contratación, se establece la necesidad de que, aquellas empresas que adopten este tipo de contratación aseguren, entro otros aspectos, "la existencia de un proceso tutorial, realizado por una persona capacitada para ello, que facilite el proceso de aprendizaje en el puesto de trabajo"42.

En la misma dirección de garantizar el buen ejercicio de la función del tutor en las prácticas no laborales se ha propuesto la necesidad de "exigir progresivamente un título especial para ser tutor de prácticas, tanto para los académicos como para los tutores profesionales". A tal efecto se recuerda que en Alemania en el sistema de formación dual el título de Meister califica a los tutores con un examen teórico-práctico, donde además de conocimientos profesionales se exigen conocimientos pedagógicos y de administración de empresa. En contrapartida, estos profesionales gozan de gran prestigio y están mejor retribuidos ${ }^{43}$. En la misma dirección, pero tomando como referencia el sistema de formación dual en Holanda, se considera que "las empresas no deberian poder formar (...) mediante becas de trabajo, sin ser acreditadas previamente, respecto a que cuentan con instalaciones y personal preparado. A tal efecto, también se considera que la empresa debería contar con tutores que tuvieran conocimientos pedagógicos además de conocimientos prácticos" ${ }^{\text {. }}$.

Finalmente, en la misma dirección de fomentar el buen funcionamiento de las prácticas no laborales a través de su reconocimiento se encuentra el artículo 18.2 del Real Decreto 592/2014 al establecer que "el Ministerio de Educación, en colaboración con las Comunidades Autónomas y el Consejo de Universidades, promoverá la difusión

\footnotetext{
41 Vid. BOE de 22 de julio de 2019. Vid. también, artículo 96 del Convenio colectivo general de la industria textil y de la confección (BOE de 16 de julio de 2019).

${ }^{42}$ Vid. BOE de 5 de junio de 2019.

${ }^{43}$ Vid. Esteve SEgARRA, A., “Claves para un estatuto de los becarios...” cit., pág. 37.

44 Todolí Signes, A., "La formación dual en Holanda. ¿Hacia un contrato para la formación y el aprendizaje en las Universidades?”, Trabajo y Derecho, núm. 36, 2017, págs. 47 y ss.
} 
pública de la relación de las entidades colaboradoras en las que realicen prácticas académicas externas los estudiantes de cada universidad, así como el reconocimiento público de aquellas empresas, instituciones o entidades cuyas prácticas alcancen mayores niveles de calidad"45.

Sin lugar a dudas, la generalización de medidas como las expuestas dirigidas a poner en valor la función de los tutores de las prácticas no laborales de estudiantes universitarios y titulados recientes contribuiría de un modo decisivo a potenciar esta figura, asegurando el correcto cumplimiento de su función de tutorización, y al mismo tiempo permitiría delimitar mejor las prácticas no laborales desarrolladas por estos colectivos de aquellas prestaciones de servicios que, por el contrario, deben ser calificadas como auténticas relaciones laborales.

\section{Referencias bibliográficas}

AAVV., El sistema de becas en la primera inserción y su relación con el empleo, Ministerio de Trabajo y Asuntos Sociales, Madrid, 2006.

Ahumada Villalba, B., "La beca de formación práctica con prestación de servicios", Relaciones Laborales, 1999-I.

Álvarez GiMeno, R., "La inserción de los jóvenes profesionales cualificados en el mercado de trabajo", en Estrategia Europea, Estado Autonómico y Política de Empleo. XVIII Congreso Nacional de Derecho del Trabajo y de la Seguridad Social, Ministerio de Trabajo e Inmigración, Madrid, 2008.

BAVIERA PUIG, I., "Las prácticas formativas para estudiantes universitarios en el EEES", Aranzadi Social, núm. 2, 2011.

CRUZ Villalón, J., "Empleo y crisis económica”, en GonZÁlez-Posada MARTínez, E. Y Molero Marañón, M.L. (Dirs.): Derecho del Trabajo, Constitución y crisis económica. Estudios en homenaje al profesor Fernando Valdés Dal-Ré. Revista Universitaria de Ciencias del Trabajo-Universidad de Valladolid, Valladolid, 2014.

\footnotetext{
${ }^{45}$ En la misma dirección, como señala PRIETO PADÍN, P., "Adquisición de competencias profesionales de los estudiantes..." cit., pág. 257, "algunas universidades quieren incentivar y reconocer la calidad de las prácticas académicas externas, convocando premios a favor tanto de aquellas empresas e instituciones que han destacado por su apoyo al programa de prácticas, como a los estudiantes que han obtenido una mejor calificación".
} 
De La Puebla Pinilla, A., "Problemas prácticos de las prácticas no laborales en empresas”, en García Perrote, I. y Mercader Uguina, J.R. (Dirs.), Las reformas laborales y de Seguridad Social. De la Ley 11/2013 de 26 de julio al Real Decreto Ley 3/2014, de 28 de febrero, Lex Nova-Thomson Reuters, Valladolid, 2014.

De VAL TenA, A.L., “Trabajo en prácticas y prácticas no laborales”, Documentación Laboral, núm. 104, 2015.

DuQue GonZÁlez, M., Becas y becarios: camino de su regulación laboral, Lex NovaThomson Reuters, Valladolid, 2012.

Esteve Segarra, A, "Claves para un estatuto de los becarios y la mejora de los períodos de prácticas académicas a partir del análisis de los "stages" franceses", Trabajo y Derecho, núm. 33, 2017.

FERNÁNDEZ MÁRQUEZ, O., "Nuevas normas sobre los becarios y el personal sanitarios residente: otra ocasión para la reflexión sobre el "trabajo formativo"”, Temas Laborales, núm. 74, 2004.

FERNÁNDEZ MÁRQUEZ, O., "La relación laboral como ámbito del trabajo formativo", Revista Española de Derecho del Trabajo, núm. 124, 2004.

FERNÁNDEZ ORRICO, F.J., "La Seguridad Social de quienes participan en programas de formación, y otras tres figuras cercanas", Revista de Información Laboral, núm. 9, 2012.

Guindo Morales, S. y Ortega Lozano, P.G., "El régimen jurídico de seguridad social de las prácticas remuneradas y de las prácticas no remuneradas: la nueva obligación de cotizar en ambos regímenes como sujetos asimilados a trabajadores por cuenta ajena", Revista General de Derecho del Trabajo y de la Seguridad Social, núm. $52,2019$.

GOÑI SEIN, J.L., "La inserción profesional de los jóvenes en la empresa a través de las becas", Relaciones Laborales, 1986-II.

Martín VAlVERde, A., "Beca de estudios técnico-prácticos con opción de reingreso en una entidad bancaria”, Revista de Política Social, núm. 99, 1973.

Martín VAlverde, A., "Fronteras y "zonas grises" del Derecho del Trabajo en la jurisprudencia actual (1980-2001)", Revista del Ministerio de Trabajo y Asuntos Sociales, núm. 38, 2003. 
Molina Hermosilla, O., "Becas de formación convocadas por las universidades: ¿una contribución efectiva a la formación práctica de sus estudiantes? Análisis y propuestas para su adecuada regulación", Revista General de Derecho del Trabajo y de la Seguridad Social, núm. 51, 2018.

Moreno GenÉ, J., "La regulación de las prácticas no laborales en empresa en el Real Decreto 1543/2011: ¿un sucedáneo de contrato en prácticas?”, Revista de Trabajo y Seguridad Social. CEF, núm. 347, 2012.

MoReno Gené, J., "La nueva regulación de las prácticas académicas externas de los estudiantes universitarios: la potenciación de la finalidad formativa y de mejora de la empleabilidad”, Revista de Trabajo y Seguridad Social. CEF, núm. 349, 2012

MoRENO GENÉ, J., “Las estancias prácticas no laborales en el entorno profesional de los jóvenes y su protección social”, en Moreno Gené, J. Y RoMero Burillo, A.M. (Coords.), Empleo juvenil. Entre el desempleo y la precariedad, Tirant lo Blanch, Valencia, 2016.

MoRENO GENÉ, J., "Las estancias prácticas no laborales en el entorno profesional como mecanismo de transición de los jóvenes de la formación al trabajo", en MORENO GENÉ, J. y FERNÁNDEZ Villazón, L. (Dirs.), Crisis de empleo, integración y vulnerabilidad social, Thomson Reuters-Aranzadi, Cizur Menor (Navarra), 2017.

Moreno GenÉ, J., "El recurso fraudulento a las prácticas no laborales en empresas previstas en el Real Decreto 1543/2011 y sus efectos. A propósito de la STSJ de Asturias de 20 de septiembre de 2016", Revista General de Derecho del Trabajo y de la Seguridad Social, núm. 46, 2017.

MORENO GENÉ, J., Las prácticas académicas externas de los estudiantes universitarios: aspectos jurídico-laborales y de Seguridad Social, Tirant lo Blanch, Valencia, 2017.

MuÑOz RuIZ, A.B., "Buenas prácticas relativas a la formación profesional dual en la negociación colectiva”, Revista de Información Laboral, núm. 4, 2014.

ORTEGa LOZANO, P.G., "La delgada línea divisoria entre una relación laboral asalariada y la remuneración o contraprestación económica del becario como zona gris del Derecho del Trabajo", Revista Española de Derecho del Trabajo, núm. 218, 2019.

PoQuet CATAlÀ, R., “Zona gris entre la relación de becario y la relación laboral común y protección social actual”, Revista Española de Derecho del Trabajo, núm. 192, 2016. 
Prieto Padín, P., “Adquisición de competencias profesionales de los estudiantes de formación profesional y universitarios mediante la combinación de experiencia (pre)laboral y formación práctica", en AA.VV. (FERnÁndeZ FERnÁNDEZ, R., Dir. y Álvarez Cuesta, H., Coord.), Empleo juvenil: un reto para Europa, Cizur Menor (Aranzadi), 2016.

SÁNCHEZ PÉREZ, J., "Cuatro razones para declarar la inconstitucionalidad e ilegalidad de la regulación reglamentaria de las prácticas no laborales (RD 1543/2011)", Revista General de Derecho y de la Seguridad Social, núm. 38, 2014.

SÁNCHEZ PÉREZ, J., "Prácticas no laborales: avances y retrocesos en el derecho del trabajo", en MONEREO PÉREZ, J.L. (Coord.). Retos del Derecho del Trabajo frente al desempleo juvenil, Consejo Andaluz de Relaciones Laborales, Sevilla, 2014.

SÁnchez-Rodas NAVARro, C., "Formas no laborales de inserción de los jóvenes en el mercado de trabajo", en Monereo PÉREz, J.L. (Coord.): Retos del Derecho del Trabajo frente al desempleo juvenil, Consejo Andaluz de Relaciones Laborales, Sevilla, 2014.

Selma Penalva, A., "Los becarios aparentes. Comentario a la STSJ del País Vasco, de 18 de marzo de 2003 (AS 2003, 2567), Aranzadi Social, núm. 14, 2003.

Selma Peñalva, A., Los límites del contrato de trabajo en la jurisprudencia española, Tirant Monografías, Valencia, 2007.

Sempere Navarro, A.V., (Dir.): Políticas sociolaborales, Tecnos, Madrid, 2005.

Todolí Signes, A., "La compleja e insatisfactoria regulación de las prácticas y las becas de trabajo", Trabajo y Derecho, núm. 6, 2015.

Todolí Signes, A., "La formación dual en Holanda. ¿Hacia un contrato para la formación y el aprendizaje en las Universidades?”, Trabajo y Derecho, núm. 36, 2017. 